\title{
BENEFÍCIOS AMBIENTAIS E ECONOMICOS PROVENIENTES DA IMPLEMENTAÇÃO DA PRODUÇÃO MAIS LIMPA EM UMA INDÚSTRIA DE MÓVEIS DE NATAL-RN
}

\author{
P. P. S. Leite ${ }^{1}$ H. C. D. Pimenta ${ }^{2}$ \\ ${ }^{1}$ Mining Ventures Brasil \\ hutz_pxp@hotmail.com, \\ 2Instituto Federal do Rio Grande do Norte - Núcleo de Estudos em Sustentabilidade \\ Empresarial \\ handson.pimenta@ifrn.edu.br
}

Artigo submetido em março/2011 e aceito em abril/2011

\begin{abstract}
RESUMO
O presente trabalho teve como objetivo geral analisar os benefícios ambientais e econômicos obtidos através da implementação da Produção mais Limpa $(\mathrm{P}+\mathrm{L})$ em uma indústria de móveis localizada em Natal-RN. Trata-se de um estudo de caso que contou com uma revisão bibliográfica sobre o setor e a $\mathrm{P}+\mathrm{L}$ e uma pesquisa de campo que contemplou as seguintes etapas: diagnóstico ambiental e operacional da empresa (estudo de arranjo físico, levantamento de métodos, fluxograma especifico do processo produtivo, levantamento de aspectos e impactos); levantamento de desperdícios; estudo de oportunidades de melhorias; implementação e monitoramento. Os resultados do diagnostico mostram desperdícios representativos de insumos (MDF, cola, lixa, etc), além da desorganização do espaço físico da empresa, insalubridade do galpão de produção. Assim, foram implementadas algumas medidas de otimização do uso de MDF, cola, lixa, além da implementação de um sistema de coleta de serragem e sistematização da produção, além do reaproveitamento de aparas de MDF para fabricação de chapas recicladas. Nesse contexto, as oportunidades de melhoria ambiental contemplaram os níveis 1 (redução na fonte) e nível 2 (reciclagem interna) acarretando na otimização do uso de recursos e a diminuição da poluição gerada, trazendo um alavancar uma receita anual para empresa aproximadamente em $\mathrm{R} \$ 3.600$ a partir de um investimento de $\mathrm{R} \$ 4311$, tendo um período de retorno não superior à 2 anos em cada estudo. Por fim, verifica-se que com a implementação das atividades vislumbradas é possível observar uma economia significativa nos gastos da empresa além dos benefícios operacionais como melhoria do ambiente de trabalho e mudanças benéficas no quesito meio ambiente através da diminuição do consumo de matéria prima e da geração de resíduos.
\end{abstract}

PALAVRAS-CHAVE: Gestão ambiental empresarial; Produção mais limpa, Adequação ambiental e operacional, Indústria moveleira.

\section{ENVIRONMENTAL AND ECONOMIC BENEFITS FROM THE CLEANER PRODUCTION IMPLEMENTATION WITHIN FURNITURE MANUFACTURE FROM NATAL-RN}

\begin{abstract}
This study aimed to analyze the environmental and economic benefits achieved through the Cleaner Production (CP) implementation within a small furniture manufacture from Natal,
\end{abstract}


Brazil. This is a case study which included a literature review on the furniture manufacture and CP and a survey which covered the following steps: Environmental and operational analysis - EOA (process flow diagrams, inputs and outputs information, mass balance, environmental aspect and impact analysis, waste studies), Feasibility analysis (technical, economic and environmental analysis, select options for implementation), Implementation and Evaluate performance. The results of EOA pointed out a representative waste of raw materials, such as MDF, glue, sandpaper, etc., besides that it was observed a disorganization of the physical space and an unhealthy production. Thus, some improvement actions were implemented to optimize the glue and sandpaper usage, moreover a waste collection system and a reuse system of MDF for making recycled plates were implemented. In this context, the opportunities for environmental improvement contemplated the levels 1 (source reduction) and Level 2 (internal recycling). As a result, it was noted an optimal use of resources and less pollution, bringing annual economic benefit of $\mathrm{R} \$ 3,600$ from an investment of $\mathrm{R} \$ 4,311$. In addition, the payback does not exceed two years in each study. To concludeIt was depicted that with the implementation of activities is possible to achieve significant savings as well as operational and environmental improvements.

KEY-WORDS: Environmental management, Cleaner Production, Operational and environmental adequacy, Furniture manufacture. 


\section{BENEFÍCIOS AMBIENTAIS E ECONOMICOS PROVENIENTES DA IMPLEMENTAÇÃO DA PRODUÇÃO MAIS LIMPA EM UMA INDÚSTRIA DE MÓVEIS DE MUNICIPIO DE NATAL-RN}

\section{INTRODUÇÃO}

Até os anos 60 as organizações adotavam uma forte ênfase na eficiência dos sistemas produtivos, refletindo a noção de mercados e recursos limitados. Em um curto espaço de tempo, essa noção revelou-se equivocada, porque ficou evidente que o contexto de atuação das empresas tornava-se a cada dia mais complexo e que o processo decisório sofreria restrições cada vez mais severas. Um dos componentes importantes dessa reviravolta nos modos de pensar e agir foi o crescimento da consciência ecológica, na sociedade, governo e nas próprias empresas, que passaram a incorporar essa orientação em suas estratégias (DONAIRE, 1999).

Além das preocupações com as questões ambientais, tais como a escassez dos recursos naturais e a qualidade ambiental da comunidade as empresas estão buscando uma adequação ambiental de seus processos e produtos com o objetivo de obter um diferencial no mercado competitivo através do marketing verde ou benefícios fiscais obtidos com a adequação ambiental.

Nessa conjuntura, a Produção mais Limpa - P+L, aponta como uma ferramenta favorável a atuação das empresas de forma preventiva em relação aos seus aspectos ambientais, agindo através da minimização de impactos associados à minimização de custo e otimização de processos, recuperação e otimização do uso de matérias-primas e energia, tendo de forma geral ganho de produtividade a partir de um controle ambiental preventivo (PIMENTA, 2008).

O setor moveleiro é um ramo industrial em pleno desenvolvimento no Brasil que vem ganhando espaço no mercado internacional. Isto ocorre devido à boa qualidade dos móveis, alcançado devido aos investimentos em tecnologia para o setor. Por outro lado, melhorias na gestão ambiental poderão representar não apenas a sustentabilidade dos mercados conquistados, bem como novos ganhos de competitividade, através de técnicas como racionalização do uso de matérias-primas, reaproveitamento e reciclagem de resíduos (SCHNEIDER; ET AL, 2003). Por sua posição estratégica, o Rio Grande do Norte tem total condição de ser um pólo exportador de móveis para o mercado nacional e também o mercado Europeu e Americano. Entretanto a baixa capacitação tecnológica associada a falta de gestão integrada de suas empresas, especialmente as pequenas e médias, dificultam a inserção da economia potiguar no mercado mundial (SANTOS, 2007).

Assim, o presente artigo tem como objetivo geral analisar os benefícios ambientais e econômicos obtidos através da implementação da Produção mais Limpa em uma indústria de móveis, localizada na zona oeste da cidade de Natal-RN. A pesquisa ainda possui como objetivos específicos: diagnosticar sob o ponto de vista operacional e ambiental o processo produtivo da empresa em estudo; identificar e analisar oportunidades de melhoria na indústria moveleira, através da implementação da P+L; identificar e apresentar os benefícios ambientais, econômicos e operacionais oriundos da implementação da ferramenta produção mais limpos no setor de produção de móveis; identificar e analisar possíveis barreiras no processo de implementação da $\mathrm{P}+\mathrm{L}$.

Trata-se de uma pesquisa exploratória desenvolvida em uma empresa de pequeno porte localizada na cidade do Natal, participante do arranjo produtivo local de móveis da grande 
Natal no Rio Grande do Norte, no qual teve a implementação do programa de $\mathrm{P}+\mathrm{L}$ modelo SEBRAE (2005) pelo Núcleo de Estudos em Sustentabilidade Empresarial - NESE do IFRN.

Contudo, para orientar a discussão proposta, o presente artigo está dividido em cinco capítulos, no qual o primeiro deles traz a problemática e os objetivos da pesquisa. $\mathrm{O}$ segundo capítulo fundamenta a ferramenta objeto do estudo. Em seguida, é apresentada a metodologia utilizada, classificando o tipo de pesquisa, estabelecendo o escopo e detalhando os procedimentos de campo. Logo depois, nos resultados e discussão, realiza-se a descrição em cima das oportunidades de $\mathrm{P}+\mathrm{L}$ vislumbradas, neste estudo de caso. Finalmente, são apresentadas as considerações finais.

\section{REVISÃO DE LITERATURA}

\section{INDÚSTRIA MOVELEIRA: QUESTÕES ECONÔMICAS E AMBIENTAIS}

A indústria de móveis caracteriza-se pela reunião de diversos processos de produção, envolvendo diferentes matérias-primas e uma diversidade de produtos finais, e pode ser segmentada principalmente em função dos materiais com que os móveis são confeccionados (madeira, metal e outros), assim como de acordo com os usos a que são destinados (em especial, móveis para residência e para escritório). Além disso, devido a aspectos técnicos e mercadológicos, as empresas, em geral, são especializadas em um ou dois tipos de móveis, como, por exemplo, de cozinha e banheiro, estofados, entre outros (GORINI, 1998).

De acordo com Valença, Pamplona e Souto (2002), a produção mundial de móveis está estimada no patamar de US\$ 200 bilhões. Nos países desenvolvidos a produção representa $79 \%$ do total mundial, sendo de $64 \%$ a parcela das sete maiores economias industriais: Estados Unidos, Itália, Japão, Alemanha, Canadá, França e Reino Unido.

No Brasil, assim como no restante do mundo, a maior parte do setor moveleiro é formado por micro e pequenas empresas e segundo dados da ABIMÓVEL (2006) existem 16.104 empresas no ramo da movelaria somando um total de 206.352 de funcionários tendo um aumento no faturamento de 65,04\% entre os anos de 2000 e 2004, assim, comprovando o crescimento do setor. Santos (2007), explica que as principais indústrias de móveis do Brasil estão localizadas nas regiões sul e sudeste e que os principais complexos moveleiros são: São Bento do Sul (SC), Bento Gonçalves (RS), Arapongas (PR), Ubá (MG), Mirassol (SP) e Votuporanga (SP), cada um deles com estruturas produtivas e linhas de produtos diferenciados.

Para a Federação das Indústrias do Rio Grande do Norte - FIERN (2004) as atividades das serrarias se iniciaram no inicio do século $\mathrm{XX}$ e a indústria moveleira do $\mathrm{RN}$ evoluiu a partir de pequenas marcenarias, atuando no segmento de móveis sob encomenda, onde o próprio dono era responsável pelo atendimento ao cliente, pela fabricação, montagem e instalação dos móveis. Este setor ainda, se caracteriza pelo predomínio de micro e pequenas empresas de tradição familiar, cuja técnica depende da criatividade dos artesões e predomina a cultura da cópia de outros modelos.

De acordo com os estudos do Pólo de Modernização Empresarial das Indústrias de Móveis de Natal - POLOEMP (1999), o setor moveleiro local atende a somente $2 \%$ da demanda de móveis do Rio Grande do Norte, ficando os $98 \%$ restantes com as empresas do sul e sudeste do país, principalmente o Rio Grande do Sul. A forma de produção dessas indústrias locais é bem diferente da forma de produção das indústrias do Sul e Sudeste - as indústrias locais produzem "móveis sob encomenda" e as do sul/sudeste "em série", com tecnologia avançada. 
De acordo com Lima e Silva (2005), com o crescimento industrial, o uso da matéria-prima vem aumentando constantemente, podendo acarretar em impactos representativos frente ao grande volume de matéria-prima florestal explorado.

Schneider et al (2003), explica que as florestas nativas e plantadas, a madeira industrializada, o Medium Density Fiberboard ou Fibra de Média Densidade (MDF), os aglomerados, e placas duras para móveis são as principais matérias-primas utilizadas pela indústria moveleira. A produção atual de madeira no Brasil representa cerca de US\$ 2,5 bilhões/ano, com 4,6 milhões de hectares de florestas plantadas, a maioria localizada nos estados do Paraná, São Paulo, Minas Gerais e Espírito Santo, sendo que as áreas de reflorestamento são constituídas principalmente por eucalipto e pinus com larga utilização pelo setor moveleiro.

Lima e Silva (2005) afirmam que os resíduos de madeira gerados pelo seu processamento podem deixar de ser um risco ao meio ambiente e passar a gerar lucro para a empresa que o produz, além de apresentar alternativas, como matéria-prima para diversos outros produtos. Com isso, pode-se diminuir o preço dos produtos feitos com ele, e reduzir a exploração da madeira virgem. E apesar de serem considerados como de baixo nível poluidor, a estocagem de resíduos de madeira ocupa espaço, o que gera problemas. Se forem queimados a céu aberto, ou em queimadores sem fins energéticos, vão liberar gases para o ambiente, tornandose potenciais poluidores.

Schneider et al (2003), explica que as tentativas de análise global do problema da geração de resíduos pela indústria moveleira tornam-se difíceis, no entanto, face à ausência de uma estimativa oficial e atualizada, em nível nacional ou regional, sobre o volume de resíduos gerado pelas empresas do setor. Em adição, o diagnóstico da geração de resíduos neste caso passa a ser fundamental para a tomada de decisão na determinação da gestão dos resíduos. Em alguns casos, o aproveitamento dos resíduos está condicionado a economias de grande escala, como é o caso da indústria de aglomerados que, apesar de ter surgido na Europa com a finalidade de aproveitamento dos resíduos industriais e das serrarias, no Brasil se utiliza preferencialmente de cavacos de madeira roliça oriunda de florestas.

\section{PRODUÇÃO MAIS LIMPA COMO UMA FERRAMENTA DA GESTÃO AMBIENTAL EMPRESARIAL}

Para Barbieri (2007), as organizações produtivas devem desenvolver um conjunto de atividades administrativas e operacionais para abordar problemas ambientais decorrentes da sua atuação ou para evitar que eles ocorram no futuro. Ela pode desenvolver através de abordagens de gestão corretivas (controle da poluição gerada e remedição de áreas degradadas), preventivas (uso eficiente de insumos) e estratégica (antecipação à problemas e busca de diferenciais competitivos).

Nesse contexto, aplicação da ferramenta Produção mais Limpa pode ser classificada como uma abordagem preventiva e estratégica já que segundo Schenini (2005), a P+L faz parte das novas estratégias de administração industrial e propõe o uso de conceitos que aumentam a eficiência e previnem a poluição na fonte, reduzindo ou evitando riscos para a população humana, em especial, e o ambiente em geral.

A Produção Mais Limpa foi definida em um seminário realizado pelo Programa das Nações Unidas para o Meio Ambiente (PNUMA) em 1990, como uma abordagem de proteção ambiental ampla que considera todas as fases do processo de manufatura ou ciclo de vida do produto, com o objetivo de prevenir e minimizar os riscos para os seres humanos e o 
ambiente, a curto e a longo prazos. Essa abordagem requer ações para minimizar o consumo de energia e matéria-prima e a geração de resíduos e emissões. A P+L envolve produtos e processos e estabelece uma hierarquia de prioridades de acordo com a seguinte seqüência: prevenção, redução, reuso e reciclagem, tratamento com recuperação de materiais e energia, tratamento e disposição final (BARBIERI, 2007).

Nascimento, Lemos e Melo (2008) afirmam que a $\mathrm{P}+\mathrm{L}$ caracteriza-se pelos seguintes aspectos: (1) só a mudança tecnológica com a adoção de um programa $\mathrm{P}+\mathrm{L}$ muitas vezes não é suficiente para tornar um processo produtivo "mais limpo"; (2) a geração de conhecimento endógeno e á aplicação do know-how (saber como fazer) externo ou interno à organização são elementos-chave para o sucesso de um programa; (3) é preciso que ocorram mudanças de atitudes em todos os níveis da organização, referentes ao comprometimento com a implementação de um programa. Ainda é afirmado que A $\mathrm{P}+\mathrm{L}$ oferece oportunidades para uma relação ambiental do tipo "ganha-ganha", na qual a melhoria ambiental pode andar junto com os benefícios econômicos. Pode-se dizer, também, que existem ligações entre os objetivos comerciais e as políticas referentes às questões ambientais.

De acordo com o Centro Nacional de Tecnologias Limpas - CNTL (2003) a Produção mais Limpa é a aplicação de uma estratégia técnica, econômica e ambiental integrada aos processos e produtos, a fim de aumentar a eficiência no uso de matérias-primas, água e energia, através da não geração, minimização ou reciclagem dos resíduos e emissões geradas, com benefícios ambientais, de saúde ocupacional e econômicos.

A $\mathrm{P}+\mathrm{L}$ pode ser adotada em qualquer setor e porte de atividade a partir de uma análise técnica, econômica e ambiental detalhada do processo produtivo, objetivando a identificação de oportunidades que possibilitem melhorar a eficiência, sem acréscimo de custos para a empresa (WEIHS; WEISSEL, 2005; SILVA; MEDEIROS, 2006).

Para Glavic e Lukman (2006), a P+L inclui tanto uma condição para atingir melhorias ambientais no processo e desenvolvimento de produtos, e uma contribuição para uma maior sustentabilidade do mundo. Silva Filho e Sicsú (2003, p. 4) complementam "a P+L possibilita o funcionamento da empresa de modo social e ambientalmente responsável, ocasionando também influência em melhorias econômicas e tecnológicas".

Os programas de $\mathrm{P}+\mathrm{L}$ têm como foco o potencial de ganhos diretos no mesmo processo de produção e de ganho indireto pela eliminação de custos associados ao tratamento e à disposição final de resíduos, desde a fonte, ao menor custo, e com períodos curtos de amortização dos investimentos (NASCIMENTO; LEMOS; MELO, 2008).

A figura 1 apresenta os diferentes níveis de produção mais limpa. As alternativas do nível 1 , que constituem a prioridade máxima, envolvem modificações em produtos e processos com o objetivo de reduzir emissões e resíduos na fonte, bem como eliminar ou diminuir a sua toxicidade. As emissões e os resíduos que continuam sendo gerados devem ser reutilizados internamente, o segundo nível de prioridade. O nível 3 ocorre quando a emissão ou o resíduo produzido não tem como ser aproveitado pela própria unidade produtiva que o gerou. Nesse caso, a alternativa é a reciclagem externa, isto é, vendendo ou doando os resíduos para quem possa utilizá-los, ou, se isso ainda não for possível, eles devem ser tratados com vistas à sua disposição final em lugar seguro. 


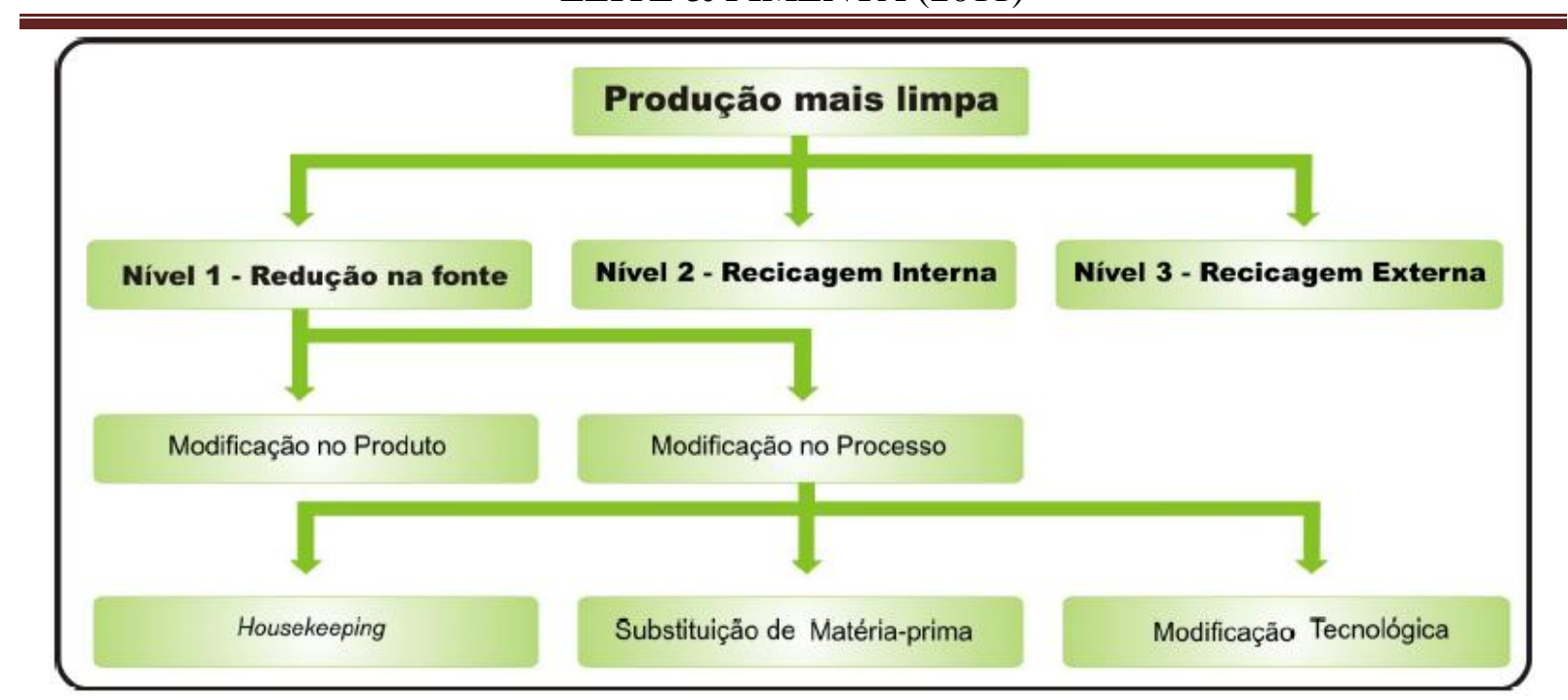

Figura 1: Níveis da Produção mais Limpa

Fonte: Adaptado de SEBRAE (2005).

\section{METODOLOGIA}

\section{CLASSIFICAÇÃO E DELIMITAÇÃO DA PESQUISA}

A classificação da pesquisa foi embasada na metodologia de Silva e Menezes (2001), as quais entendem que as formas clássicas de classificação da pesquisa obedecem alguns pontos de vista, como os da natureza da pesquisa, da forma de abordagem do problema, dos objetivos e dos procedimentos técnicos. Assim, o presente estudo é classificado como uma pesquisa explicativa, aplicada e quantitativa uma vez que foi realizado um estudo profundo detalhado sobre um tema, onde foi possível traduzir em números opiniões, informações e resultados com o objetivo de identificar os fatores que determinam ou contribuem para a ocorrência dos fenômenos e a partir daí gerar conhecimento para encontrar soluções práticas para um problema específico.

Os procedimentos de campo ocorreram entre os meses de outubro de 2007 à janeiro de 2008 em uma indústria de móveis, localizada em uma área residencial na região leste da grande Natal no estado do Rio Grande do Norte. A empresa iniciada 2002 possui 100\% de sua produção voltada para a fabricação de móveis sob encomenda e tem como principal matéria prima o MDF e possui 34 funcionários, onde 32 destes trabalham na produção e 2 na administração. Esta empresa é integrante do arranjo produtivo local de móveis da grande Natal no Rio Grande do Norte, no qual foi implementado o programa de P+L modelo SEBRAE (2005) pelo Núcleo de Estudos em Sustentabilidade Empresarial - NESE do IFRN. 


\section{PROCEDIMENTO DE CAMPO}

O estudo em tela seguiu o modelo de P+L SEBRAE (2005), tendo as seguintes etapas (Figura 2):

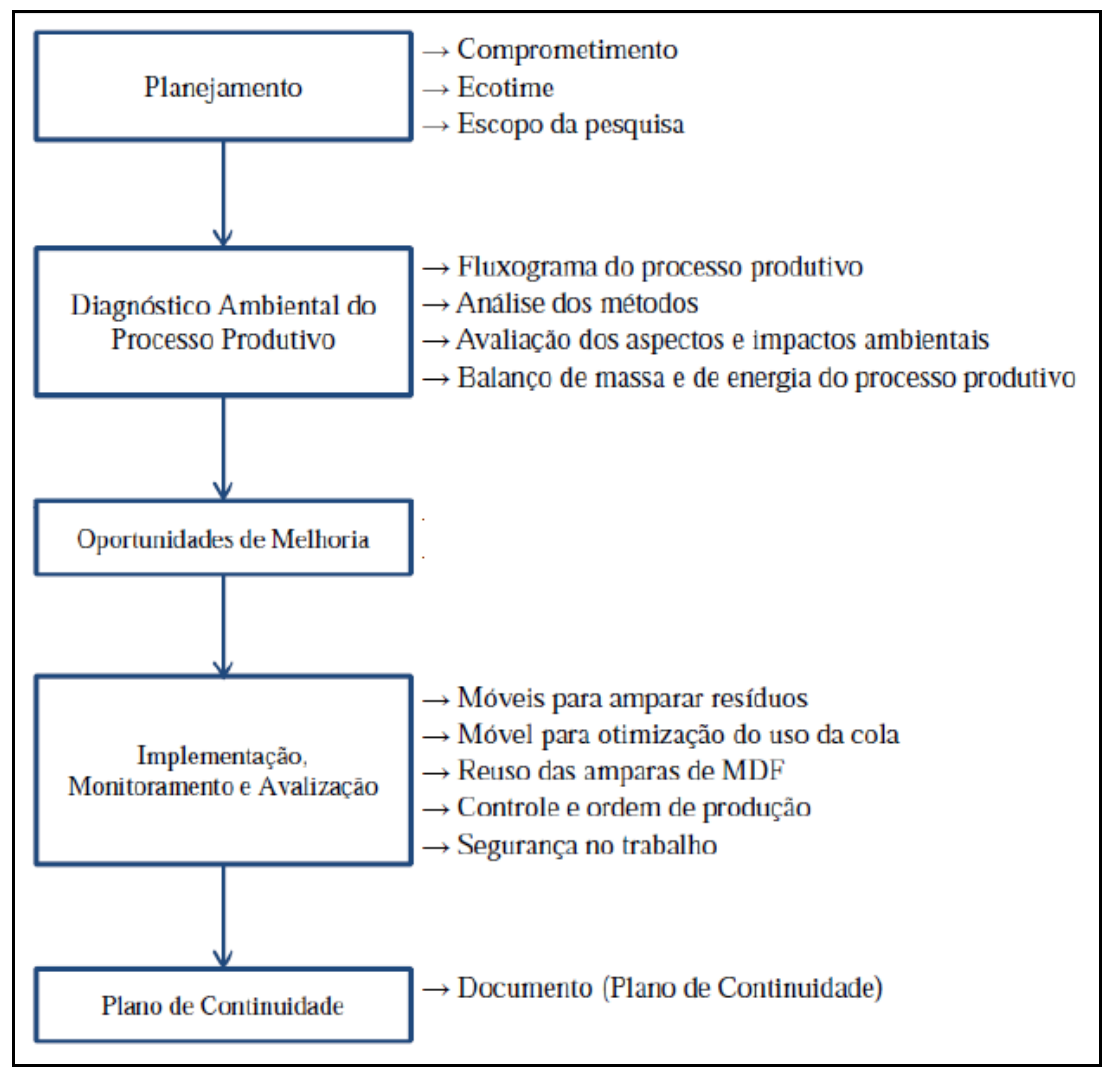

Figura 2: Procedimentos de Campo

\section{PLANEJAMENTO (COMPROMETIMENTO, ESCOPO E DEFINIÇÃO DE RECURSOS)}

Nesta etapa, buscou-se o comprometimento da alta administração, a sensibilização dos funcionários, além da formação do ecotime, equipe formada por funcionários da empresa com o objetivo de auxiliar nas identificações de oportunidades de melhoria, nas implementações das atividades propostas, na conscientização dos demais funcionários e como objetivo maior esse grupo ficou responsável por dar continuidade às ações propostas após o termino do projeto.

Quanto à definição do escopo da pesquisa, foram investigados todos os processos, uma vez que a empresa produz moveis por encomenda e não ter sido possível uma investigação minuciosa da produção de um único produto. Na definição dos recursos, foi levantada a necessidade da utilização de uma equipe externa para levantamento dos indicadores ambientais com um nível de confiabilidade mais representativo e materiais como cronômetros, calculadoras, pranchetas entre outros.

\section{DIAGNÓSTICO AMBIENTAL DO PROCESSO PRODUTIVO}

O diagnóstico foi realizado através das seguintes atividades:

- Definição do fluxograma do processo produtivo: Segundo Slack e Johnston (1997) é uma técnica de mapeamento que permite o registro de ações de algum tipo e pontos de tomada de decisão que ocorrem no fluxo real, e ainda segundo o mesmo, o fluxograma dá uma compreensão detalhada das partes do processo em que algum tipo de fluxo ocorre. 
- Análise de métodos: Realizado através de uma planilha onde são avaliados os procedimentos de execução de uma determinada atividade, auxiliando a identificação de gargalos como desperdício.

- Avaliação dos aspectos e impactos ambientais: É conseguido por meio de uma planilha que analisa os aspectos e impactos da produção através da adição de notas aos seguintes critérios: severidade, medida em função da intensidade do impacto considerando a capacidade do meio ambiente de suportá-lo ou reverter seus efeitos, restabelecendo a condição original; probabilidade, frequiência de ocorrência do aspecto associado ao impacto analisado; importância do impacto, medido pelo produto resultante da severidade e da probabilidade; existência de requisitos legais, investigação do relacionamento do aspecto com algum requisito legal e existência de medidas de controle, ações existentes na empresa com o objetivo de evitar ou minimizar o impacto, por meio do controle do aspecto impactante (CNTL, 2003). A análise realizada a partir destes critérios apontou prioridades a serem estudadas, que seriam os pontos fracos na relação da empresa com o meio ambiente.

- Balanço de massa e de energia do processo produtivo: Consiste em uma análise quantitativa dos insumos utilizados na empresa e dos resíduos gerados provenientes destes insumos. O processo de coleta foi efetuado durante quatro semanas.

\section{OPORTUNIDADES DE MELHORIA}

Esta etapa foi composta das seguintes atividades: Obtenção de uma compreensão detalhada das fontes e causas da geração de resíduos/poluição ambiental e a avaliação técnica, econômica e ambiental das oportunidades identificadas, que consiste na analise destas segundo critérios técnicos e ambientais. Para a análise econômica algumas variáveis foram consideradas como o custo dos desperdícios relacionados a variáveis ambientais da empresa, o investimento necessário para as implementações e beneficio econômico gerado pelas implementações e a análise de payback.

\section{IMPLEMENTAÇÃO, MONITORAMENTO E AVALIAÇÃO}

Neste momento, as oportunidades de melhoria vislumbradas foram aplicadas e monitoradas para saber se realmente estão obtendo o êxito desejado. Após a implementação, estas atividades foram avaliadas, seguindo os critérios ambientais, econômicos e operacionais buscando sua seqüência e melhoria continua.

\section{PLANO DE CONTINUIDADE}

Esta última etapa aconteceu integrada a etapa de planejamento, em que ha a capacitação dos funcionários com o objetivo de continuar o trabalho apos a implementação da P+L. O plano consiste em diretrizes propostas, a serem trabalhadas, após a implementação do programa.

\section{RESULTADOS E DISCUSSÃO \\ DESCRIÇÃO DA EMPRESA E PLANEJAMENTO}

A empresa em estudo possui $100 \%$ de sua produção baseada em móveis feitos sob encomenda onde $99 \%$ dessa produção compreendem móveis fabricados em MDF. Dentre os móveis mais fabricados encontram-se suportes para TV (em média 12 unidades por mês), portas em MDF (em média, 15 unidades por mês) e móveis para hotéis (10 unidades por mês). Além do MDF 
e do Ipê outros insumos são utilizados como Feijó, cola branca, cola fórmica, pregos, parafusos, lixas, rodízios, tintas, folheados, puxadores e dobradiças.

A empresa possui 32 funcionários, sendo 2 do setor administrativo e 30 na produção. Dentre os funcionários que atuam na produção 24 são marceneiros, 4 laqueadores e 2 auxiliares de serviços gerais.

Quanto ao programa de $\mathrm{P}+\mathrm{L}$, a etapa de planejamento teve inicio com a apresentação da metodologia a administração da empresa. Este processo, também teve como objetivo obter o comprometimento da administração da movelaria que além de obter informações sobre a metodologia, puderam ser esclarecidos sobre os benefícios oriundos da implementação, bem como casos de sucesso da implementação desta ferramenta.

$\mathrm{N}$ fase inicial também ocorreu a formação do ecotime, que contou com 5 funcionários da produção. Esta equipe passou por treinamentos sobre os temas $\mathrm{P}+\mathrm{L}$, segurança de trabalho e o programa 5's.

Nesta etapa da pesquisa, foi definido o escopo do projeto, onde foram investigados todos os processos, uma vez que a empresa produz moveis por encomenda. Na definição dos recursos, foi levantada a necessidade da utilização de uma equipe externa para levantamento dos indicadores ambientais com um nível de confiabilidade mais representativo e materiais como cronômetros, calculadoras, pranchetas entre outros.

\section{DIAGNÓSTICO AMBIENTAL DO PROCESSO PRODUTIVO}

Para a análise do processo produtivo, foi considerada todas as etapas de produção da empresa. O processo de fabricação dos móveis consiste em sete etapas, são elas: Corte da madeira, usinagem, pré-montagem do móvel, lixamento, revestimento, pintura e montagem (Figura 3). 


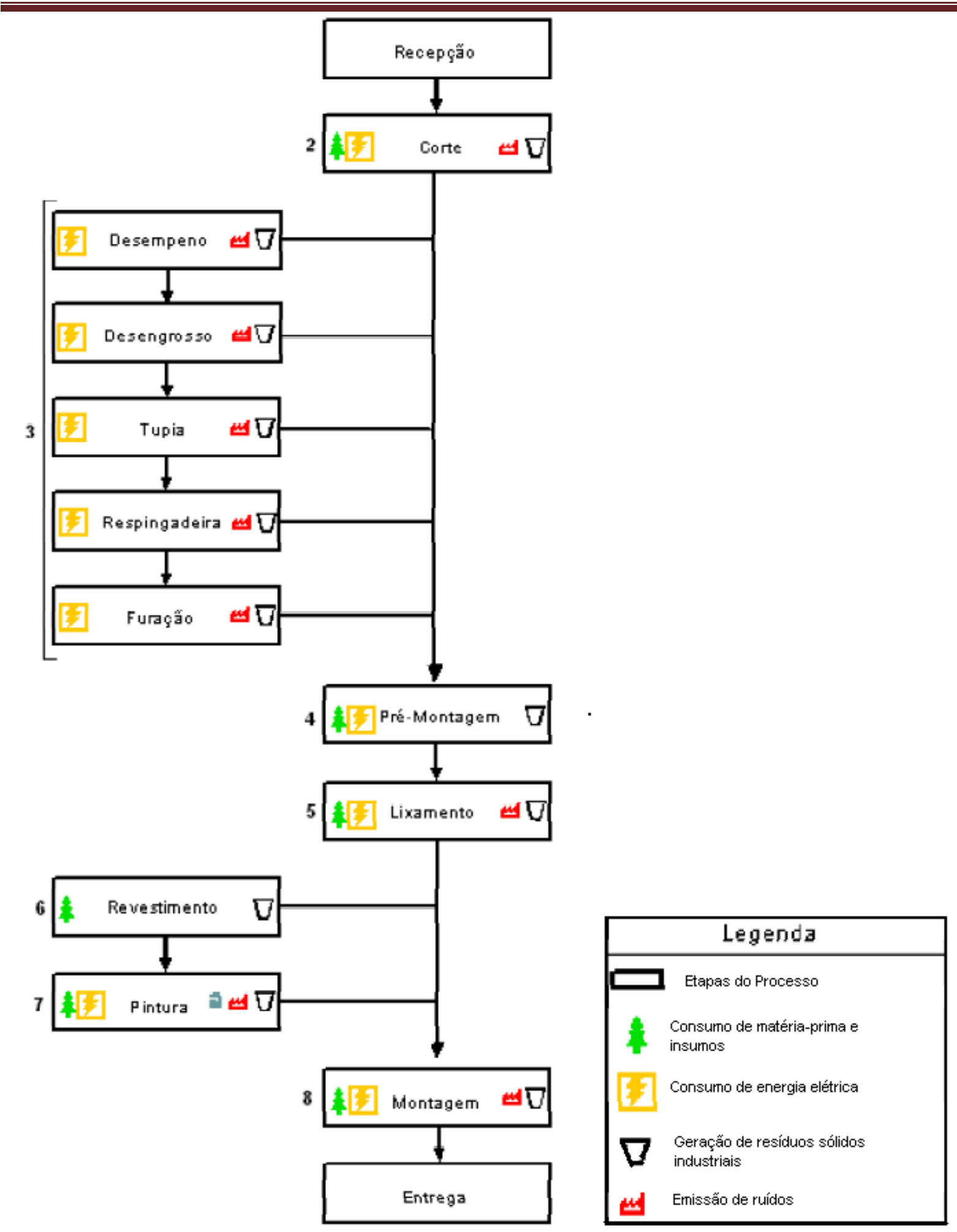

Figura 3: Fluxograma do processo produtivo.

A primeira etapa do processo produtivo da empresa é denominada de recepção e armazenamento, nessa etapa os insumos são recepcionados e armazenados em local específico, as madeiras são estocadas em uma área próxima as máquinas de corte e os outros insumos são acondicionados no almoxarifado, para a sua posterior utilização na produção de móveis. Todos os funcionários da produção se encarregam desta atividade em que não há consumo direto de matéria-prima e conseqüentemente sem geração de resíduos.

Em seguida têm a etapa de corte na qual, a madeira bruta, como o ipê e o feijó, é cortada nas serras de fita e circular, e o MDF nas serras circular e circular esquadrejadeira. As entradas 
dessa etapa são energia elétrica e madeira, e de saída, à etapa gera ruídos e resíduos sólidos como maravalhas (resíduos da madeira tipo lascas), pó de serra e aparas de madeira e MDF.

Em seguida, as madeiras cortadas são enviadas para o processo de usinagem onde serão trabalhadas com maior detalhamento recebendo as medidas certas de acordo com o projeto final. Nesse processo, maquinários como desempenadeira, desengrossadeira, a tupia, a respigadeira e as furadeiras, vertical e transversal são utilizados, acarretando em aspectos ambientais como consumo de energia elétrica, geração de ruídos e resíduos sólidos (maravalhas e pó de serra).

A quarta etapa da produção consiste na pré-montagem dos móveis, onde os marceneiros fazem uma montagem prévia do móvel a fim de verificar se as medidas dos moveis estão corretas. Nessa etapa, eles utilizam à madeira e o MDF com outros insumos como, cola branca, pregos e parafusos. Na pré-montagem, têm-se como inputs, energia elétrica, proveniente da utilização das furadeiras de mão e insumos, como saída observa-se resíduos sólidos como embalagens de cola, sacos plásticos e papelão.

A quinta etapa do processo produtivo é o lixamento, onde os marceneiros após verificarem as medidas e desmontarem os móveis, irão desenvolver um acabamento final nas peças para seguirem no processo. Nessa etapa, eles utilizam máquinas lixadeiras. As entradas dessa etapa compreendem a energia elétrica e insumos como lixa e cola e como saída têm-se, resíduos sólidos como pó, restos de lixa e embalagens de alumínio, de cola fórmica e a emissão de ruídos.

Em seguida, os móveis são encaminhados para a etapa de revestimento, no qual os marceneiros revestem os moveis com folheados de madeira ou folhas de Policloreto de Vinila (PVC). Observa-se como entrada insumos folheados, revestimento de PVC e cola fórmica já como saída têm-se resíduos sólidos como sobras de folheados e de PVC, embalagens de cola.

A sétima etapa do processo é a pintura, na qual as peças revestidas receberão verniz ou tinta. Nessa etapa, os laqueadores aplicam uma massa acrílica e logo após utilizam máquinas lixadeiras. Em seguida, se o móvel for pintado eles utilizam pistolas com 80 a 100 libras de pressão ligadas a um compressor (com $7,34 \mathrm{~kW}$ de potência). Foram identificadas como entradas desta etapa, a energia elétrica, insumos a exemplo de tinta, verniz, massa acrílica, solvente, selador e lixa e como saída têm-se, emissões de ruídos, resíduos sólidos como embalagens de tinta, de selador, de solvente e de massa acrílica e emissões atmosféricas.

A última etapa da produção é a montagem, na qual os marceneiros após receberem as peças revestidas ou pintadas montam os móveis para serem entregues aos clientes. Nesta etapa, observa-se como entrada energia elétrica, insumos como prego, parafusos e cola e como saída têm-se resíduos sólidos como embalagens plásticas, de papelão e de cola.

$\mathrm{Na}$ avaliação de aspectos e impactos ambientais, inicialmente buscou identificar os aspectos ambientais das atividades da empresa, a partir do fluxograma de processo, e posteriormente foram determinados e avaliados os impactos ambientais associados a estes aspectos. As manifestações dos impactos ambientais foram identificadas, supondo que não existia nenhuma forma de controle destes impactos, exceto aquelas que desempenhavam função essencial de processo. Após este processo, foi observado que os aspectos ambientais significativos foram: consumo de materiais, geração de ruídos e geração de resíduos sólidos. Uma forma de facilitar a interpretação dos dados, e o processo de entendimento da origem dos problemas ambientais da empresa pelos funcionários e empresário, foi inserção no fluxograma, os inputs e outputs, balanço de massa e classificação do grau de severidade dos aspectos ambientais. 


\section{OPORTUNIDADES DE MELHORIA IMPLEMENTADAS USO DE COLA (HOUSEKEEPING)}

Dentre os insumos utilizados na empresa, a cola branca é um dos mais utilizados e também um dos mais desperdiçados, sua utilização ocorre nas etapas de pré-montagem e montagem dos móveis. Na empresa, são consumidos por semana cerca de quatro tubos de cola branca com $5 \mathrm{~kg}$ cada. O desperdício acontece por não se aproveitar toda a cola do tubo, cerca de $5 \%$ de cola fica no tubo por ser um pouco mais difícil a remoção desse material restante. Cada tubo de cola custa $\mathrm{R} \$ 23,90$ e os $5 \%$ de cada tubo corresponde a $\mathrm{R} \$ 1,19$ desperdiçados, representando $\mathrm{R} \$ 240,90$ por ano. O aproveitamento total da cola branca trará, do ponto de vista ambiental, a otimização do consumo de insumos conseqüentemente diminuindo a diminuição da geração de resíduos.

Tendo observado o desperdício de cola branca, uma solução indicada por um funcionário e membro do ecotime foi utilizar um móvel para o escoamento do resto da cola no tubo (Figura 4). Quanto ao nível de P+L esta oportunidade se classifica como Housekeeping, Nível redução na fonte.

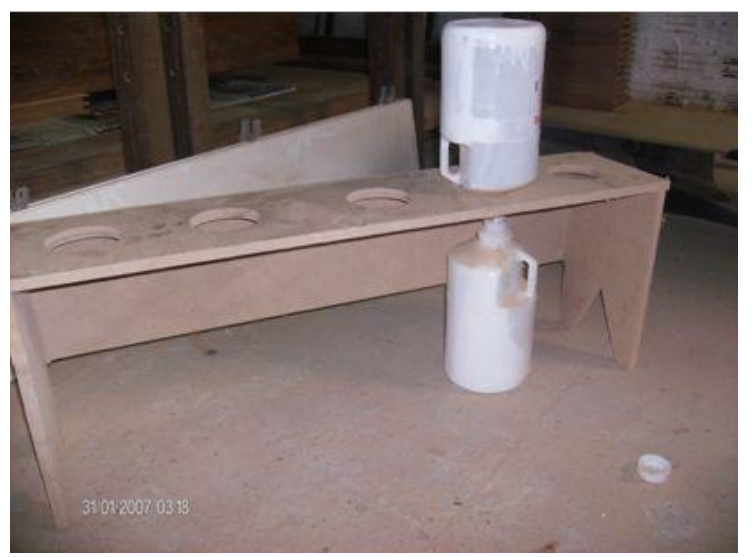

Figura 4: Móvel utilizado para aproveitar o resto de cola que ficava no fundo do tubo. (Jan. 2008).

Este móvel foi construído utilizando sobras de materiais utilizados na produção da empresa que já existiam antes do inicio do projeto, contudo para os demonstrativos a seguir, na Tabela 1 , foi utilizado um valor de investimento equivalente a insumos novos (madeira e pregos) além do tempo de mão de obra.

Tabela 1: Análise Financeira da Oportunidade - reuso de cola

\begin{tabular}{c|c|c|c}
\hline \multicolumn{2}{c|}{ Desperdício (R\$) } & $\begin{array}{c}\text { Investimento } \\
\text { (R\$) }\end{array}$ & $\begin{array}{c}\text { Pay-Back } \\
\text { (Meses) }\end{array}$ \\
\hline Mês & Ano & 19,10 & $<1$ \\
\hline 20,07 & 240,91 & & \\
\hline
\end{tabular}

Fica evidenciado pela Tabela 1 que a utilização do móvel é rentável para a empresa, e que em um mês a economia gerada por tal ação superaria o valor do investimento somado ao valor da mão-de-obra para a operação da atividade, além de que otimizando o consumo de cola branca a empresa estará diminuindo sua quantidade de resíduo gerada, ou seja, existe também um ganho ambiental. 


\section{OTIMIZAÇÃO DO USO DE LIXAS}

O desperdício de lixa foi outro ponto crítico encontrado no processo produtivo estudado. O consumo médio de lixas semanal era de 60 unidades com um custo unitário de $\mathrm{R} \$ 0,58$. As medidas da folha de lixa são $28 \times 23 \mathrm{~cm}$, sendo efetuado o corte na folhas para o uso de dois discos e em alguns casos, apenas um disco. Logo, o desperdício parte do não aproveitamento total da folha de lixa com os discos, esse desperdício está evidenciado a seguir na Figura 5 e na Tabela 2.
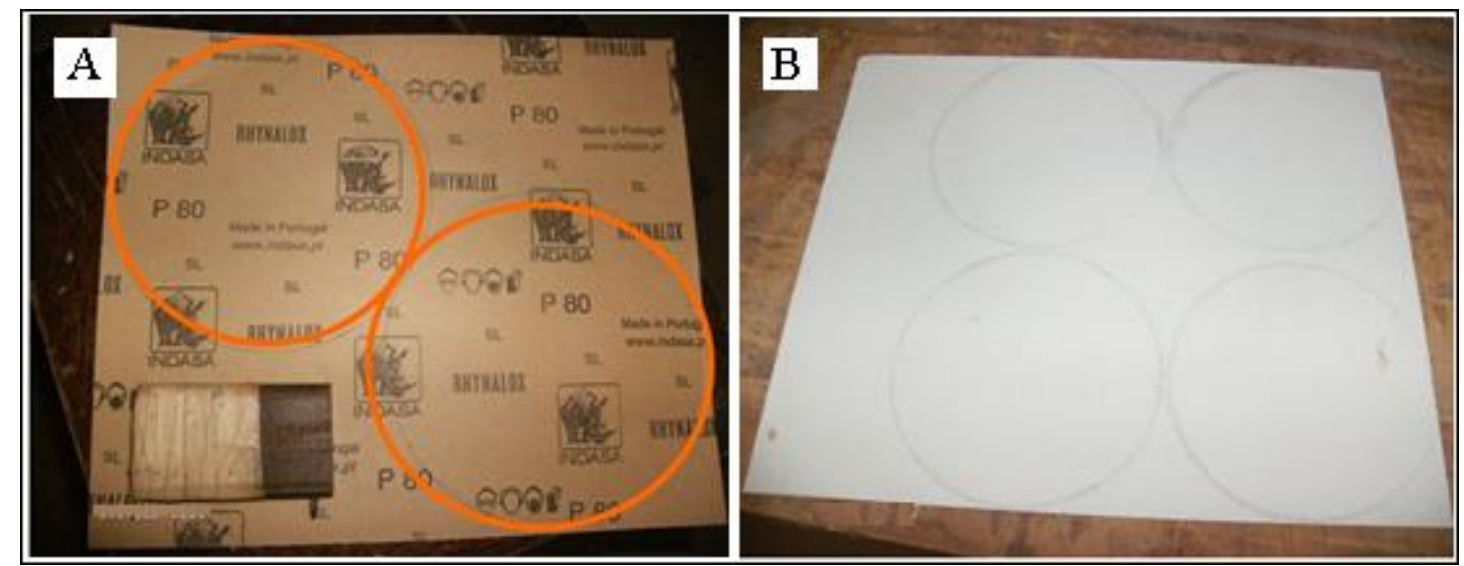

Figura 5: Folhas de lixa com demarcações dos discos de lixadeira. A - Cenário encontrado, B - Cenário proposto e adotado. (Out. 2007).

Tabela 2: Custos do desperdício de lixa para o disco maior de área igual a $167,33 \mathrm{~cm}^{2}$.

\begin{tabular}{c|c|c|c|c}
\hline \multirow{2}{*}{$\begin{array}{c}\mathbf{N}^{\circ} \text { de discos por } \\
\text { lixa }\end{array}$} & \multirow{2}{*}{ Desperdício (\%) } & \multicolumn{3}{|c}{ Desperdício (R\$) } \\
\cline { 3 - 5 } & & Semana & Mês & Ano \\
\hline 1 Disco * & 74,02 & 25,80 & 108,36 & 1300,00 \\
\hline 2 Discos * & 48,04 & 16,80 & 70,56 & 846,00 \\
\hline 4 Discos *1 & 38,84 & 13,52 & 56,77 & 681,12 \\
\hline cenários encontrados; * cenário proposto e adotado
\end{tabular}

Pela tabela acima, observa-se que ainda haverá certo desperdiço de lixa, porém com o corte de 4 lixas por folha tem-se uma otimização de $47 \%$ (quando usava-se 1 disco por folha, passando para 4) ou $20 \%$ (quando usava-se 2 discos por folha, passando para 4). Isso representa uma economia anual de $\mathrm{R} \$ 391,88$, considerando uma média aritmética entre o uso de 1 e 2 discos.

Esta oportunidade de otimização do uso das folhas de lixa configura-se também no nível de $\mathrm{P}+\mathrm{L}$ - Housekeeping, não sendo observado a necessidade de investimentos. Os benefícios surgirão com a otimização no uso folha de lixa, resultando na diminuição de gastos com a compra de lixa, além de reduzir a quantidade de resíduo gerado.

\section{REUSO DAS APARAS DE MDF}

A fim de aproveitar as aparas de MDF de $15 \mathrm{~mm}$ que sobravam da produção foi fabricada uma prensa (Figura 6) que utiliza sobras de MDF para fabricação de chapas recicladas de MDF. A Tabela 3 demonstra os gastos da fabricação da prensa e a economia obtida pela fabricação das novas chapas. Pelos resultados encontrados, constatou-se que seriam fabricadas 2 novas chapas a partir da prensa. 


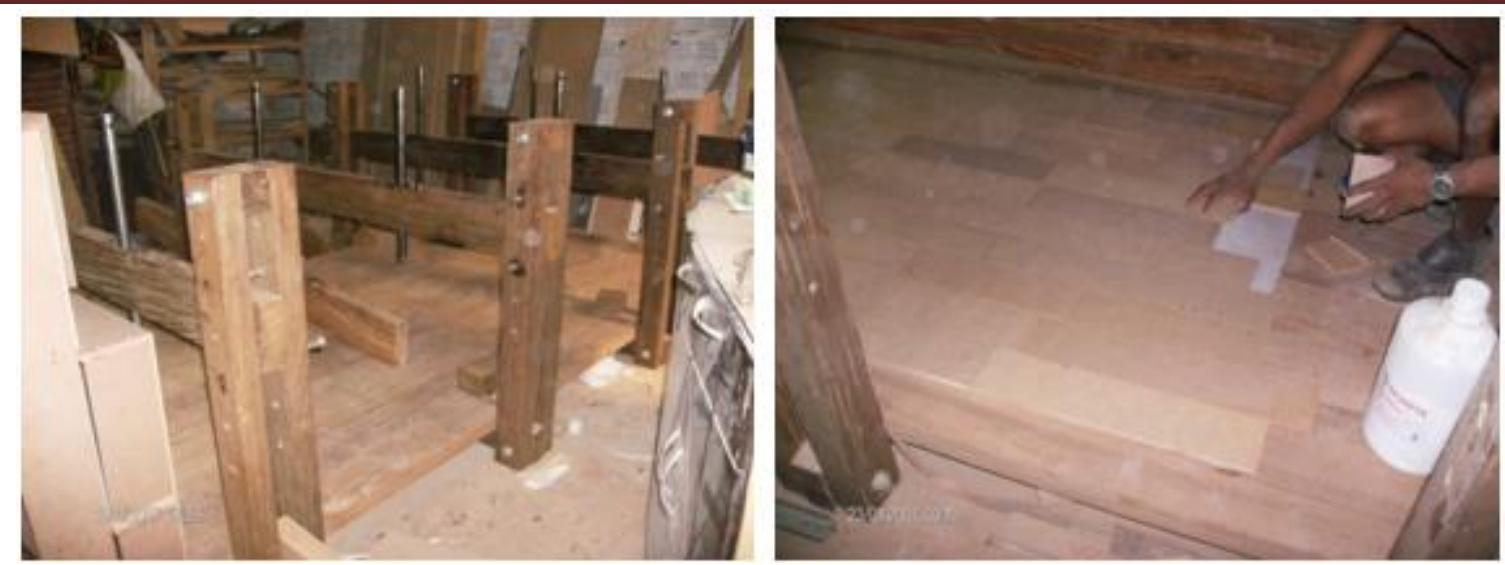

Figura 6: Fabricação de novas chapas utilizando a prensa. (Jan. 2008).

Tabela 3: Retorno financeiro pela fabricação de chapas de MDF através da prensa.

\begin{tabular}{|c|c|c|c|c|c|c|}
\hline \multirow[b]{2}{*}{$\begin{array}{c}\text { Investimento para } \\
\text { a fabricação da } \\
\text { prensa (R\$) }\end{array}$} & \multirow[b]{2}{*}{$\begin{array}{c}\text { Custo de } \\
\text { uma chapa } \\
\text { nova }(\mathbf{R} \$)\end{array}$} & \multirow{2}{*}{$\begin{array}{c}\text { Custo de } \\
\text { fabricação de uma } \\
\text { chapa na prensa } \\
(\mathrm{R} \$)\end{array}$} & \multicolumn{3}{|c|}{ Retorno financeiro (R\$) } & \multirow[b]{2}{*}{$\begin{array}{c}\text { Pay-back } \\
\text { (meses) }\end{array}$} \\
\hline & & & & & & \\
\hline 4180,00 & 93,00 & 65,00 & 56,00 & 235,2 & 2822,4 & 18 \\
\hline
\end{tabular}

O reaproveitamento de aparas de MDF para fabricação de novas chapas configura-se como Nível - Reciclagem Interna. Esta oportunidade trará para empresa um benefício financeiro de $\mathrm{R} \$ 2.822,4$ por ano, com uma rentabilidade satisfatória da prensa, já que após o primeiro ano este investimento será compensado. Outro benefício seria a retirada dessas sobras do entorno das máquinas de produção, reduzindo os riscos na operação e quanto a benefícios ambientais, haveria a diminuição do consumo de matéria-prima e da geração de resíduos.

\section{COLETA DE RESÍDUOS}

A fim de reduzir a quantidade de resíduos que se acumulam pelo chão da fábrica (Figura 7), diminuir o tempo de limpeza e aumentar a qualidade do trabalho foi instalado um sistema de coleta de serragem em três maquinários - a desengrossadeira, a tupia e a serra circular esquadrejadeira. Ou seja, este sistema teve como objetivo amparar e armazenar os resíduos das máquinas para que estes não se espalhassem pelo chão de fabrica e diminuíssem o tempo de limpeza.
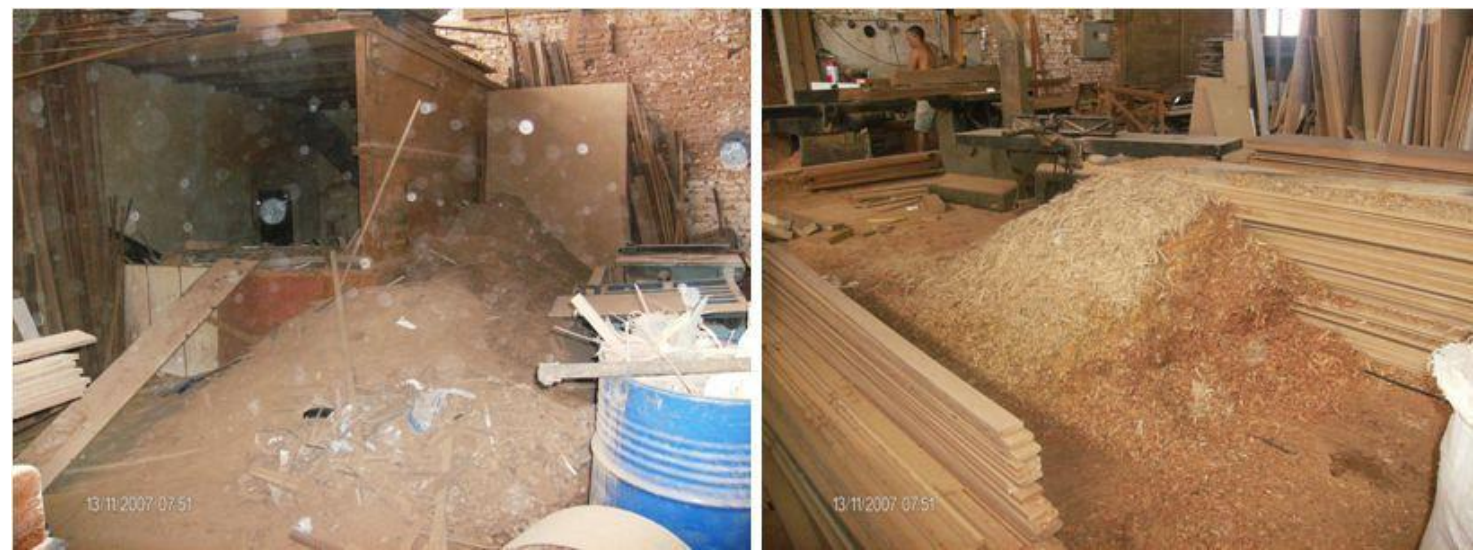

Figura 7: Resíduos da produção acumulados na fábrica. (Out./Nov. 2007). 
A seguir nas Tabelas 4 e 5, será apresentada a comparação entre os tempos e custos de limpeza antes e depois da instalação do sistema de coleta de serragem e uma análise de benefícios financeiros. Nessa análise, utilizou-se também o investimento para fabricação do sistema, mais vale ressaltar que este foi construído com sobras de materiais da produção da empresa, como MDF.

Tabela 4: Custos de mão-de-obra para limpeza das máquinas antes e depois da aplicação dos móveis Coletores de resíduos.

\begin{tabular}{c|c|c|c}
\hline Variáveis analisadas & Desengrossadeira & Tupia & Esquadrejadeira \\
\hline Tempo de limpeza antes do móvel & 22,30 min & 3,50 min & 9 min \\
\hline Custo da mão de obra (a) & $\mathrm{R} \$ 1,02$ & $\mathrm{R} \$ 0,16$ & $\mathrm{R} \$ 0,42$ \\
\hline Tempo de limpeza depois do móvel & 15 min & 1,15 min & 5 min \\
\hline Custo da mão de obra (b) & $\mathrm{R} \$ 0,69$ & $\mathrm{R} \$ 0,069$ & $\mathrm{R} \$ 0,22$ \\
\hline Beneficio (a - b) por dia & $\mathrm{R} \$ 0,33$ & $\mathrm{R} \$ 0,091$ & $\mathrm{R} \$ 0,20$ \\
\hline Beneficio ao mês & $\mathrm{R} \$ 9,70$ & $\mathrm{R} \$ 2,67$ & $\mathrm{R} \$ 5,88$ \\
\hline Beneficio ao ano & $\mathrm{R} \$ 116,42$ & $\mathrm{R} \$ 32,11$ & $\mathrm{R} \$ 70,56$ \\
\hline
\end{tabular}

* valor de mão-obra por hora $\mathrm{R} \$ 2,74$, baseado no salário dos funcionários da empresa.

Tabela 5: Avaliação do retorno financeiro da implementação dos móveis coletores de resíduos.

\begin{tabular}{c|c|c|c}
\hline Máquina & $\begin{array}{c}\text { Beneficio anual } \\
(\mathbf{R} \$ \mathbf{)}\end{array}$ & $\begin{array}{c}\text { Investimento } \\
(\mathbf{R} \$)\end{array}$ & $\begin{array}{c}\text { Pay-back } \\
\text { (meses) }\end{array}$ \\
\hline Desengrossadeira & 116,42 & $\mathrm{R} \$ 50,25$ & 5 \\
\hline Tupia & 32,11 & $\mathrm{R} \$ 21,38$ & 8 \\
\hline Esquadrejadeira & 70,56 & $\mathrm{R} \$ 41,00$ & 7 \\
\hline Total & $\mathrm{R} \$ 219,09$ & $\mathrm{R} \$ 112,63$ & - \\
\hline
\end{tabular}

As Tabelas 4 e 5 evidenciam que mesmo adicionando o custo teórico de fabricação dos móveis (Figura 8), essa ação é rentável financeiramente e que em poucos meses o custo do investimento seria compensado, alem de gerar outros benefícios como maior espaço para locomoção dos funcionários, diminuição do risco de acidentes de trabalho, tornando o ambiente de trabalho menos insalubre.
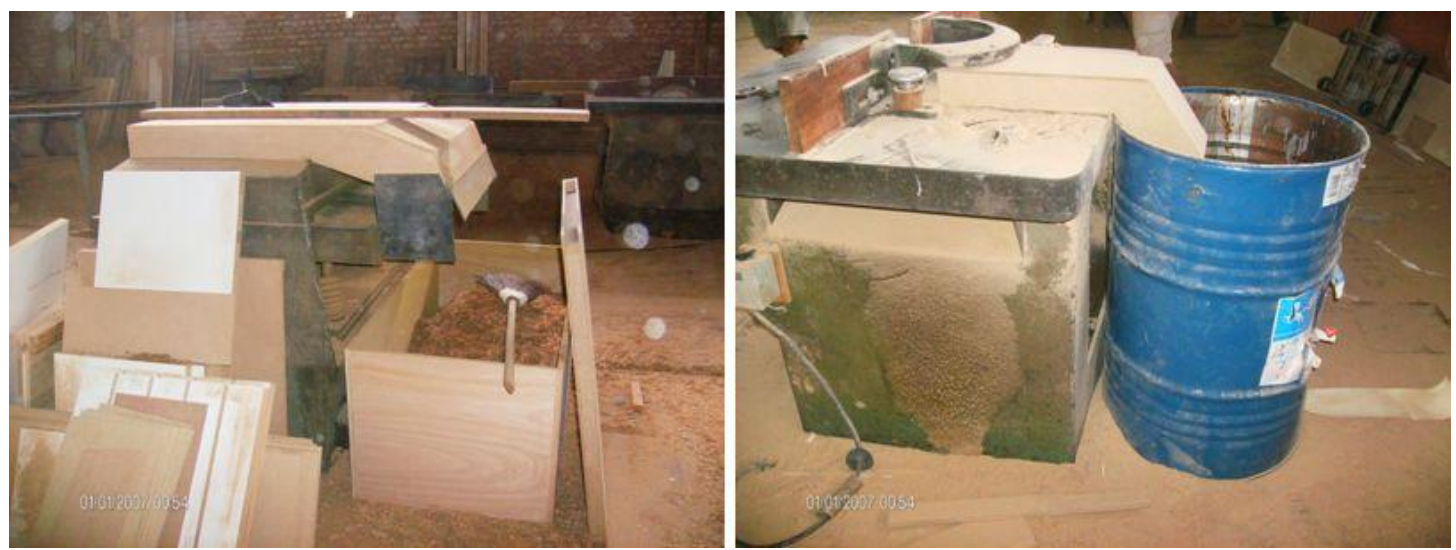

Figura 8: Móveis que amparam os resíduos gerados pela desengrossadeira e tupia. (Jan. 2008).

\section{CONTROLE E ORDEM DE PRODUÇÃO (NÃO MENSURÁVEL)}

Para otimizar o uso de controle dos insumos e do andamento da produção foram criados dois documentos, sendo uma ordem de produção padrão que passou a identificar o pedido de produção (numero de controle e dados do cliente), a data de inicio e a data prevista para entrega e todas as informações a cerca dos insumos utilizados para a fabricação do móvel. E o segundo, um controle de produção que será associado a ordem de produção e especificará os 
processos em que o móvel passará e a data de inicio de cada processo, afim de rastrear o andamento do desenvolvimento do produto em fabricação.

Espera-se que com essa implementação, haja uma melhora significativa na organização administrativa da empresa, uma otimização no consumo de insumos e conseqüentemente uma melhora nas condições ambientais da empresa através da diminuição no consumo de matériaprima e a diminuição dos resíduos poluentes gerados.

\section{BARREIRAS}

Dentre as barreiras encontradas no processo de implantação da $\mathrm{P}+\mathrm{L}$, destacam-se barreiras organizacionais e técnicas. Destaca-se que as barreiras organizacionais relacionam-se com aspectos gerenciais da organização que estão relacionados com controle dos aspectos e impactos ambientais. Já as barreiras técnicas estão relacionado aos aspectos técnicos de implementação da P+L (UNEP).

As barreiras organizacionais estavam relacionadas ao pouco tempo que o titular da empresa dispunha para tratar os assuntos relacionados ao projeto, em parte devido as demais atividades da empresa que estavam ao seu encargo e que consumiam bastante tempo e que talvez um grau de importância maior à sua visão. Além disso, todas as atividades propostas pela equipe tinham que ter o conhecimento e o aval do empresário para que pudessem ser postas em prática e por não ter um tempo maior da atenção do empresário e que algumas ações não puderam seriam implementadas.

Em relação às barreias técnicas, ocorreu uma certa resistência dos funcionários para auxiliar em algumas atividades propostas pelo projeto, como o mutirão de limpeza, pois a maior parte dos funcionários que trabalhavam no galpão de produção eram marceneiros e laqueadores e estavam fabricando móveis e não tinham ordens de parar seu trabalho para ajudar as atividades propostas, enquanto que os demais funcionários, os auxiliares de serviços gerais, passavam a maior parte do dia trabalhando nas entregas dos móveis assim não sobravam funcionários que pudessem ajudar, dificultando assim as implementações das ações encontradas como soluções para a empresa.

\section{AVALIAÇÃO CRÍTICA DA IMPLEMENTAÇÃO}

As oportunidades vislumbradas neste estudo de caso permeiam o nível 1 (redução na fonte) da $\mathrm{P}+\mathrm{L}$, principalmente através de práticas de housekeeping como a otimização do uso da cola, lixa, além da implementação de um sistema de coleta de serragem e sistematização da produção. Em adição, também as oportunidades também contemplaram o nível 2 (reciclagem interna) através da fabricação de chapas recicladas de MDF.

De forma geral, os benefícios ambientais vislumbrados estavam relacionados à otimização do uso de recursos e a diminuição da poluição gerada. Já em relação aos benefícios econômicos foi possível alavancar uma receita anual para empresa aproximadamente em $\mathrm{R} \$ 3.600$ a partir de um investimento de $\mathrm{R} \$ 4311$, conforme observa-se na tabela 6. Estes resultados convergem com os objetivos da P+L propostos pela UNIDO (2002), a saber: a) aumentar a produtividade, assegurando um uso mais eficiente da matéria-prima, energia e água; b) promover um melhor desempenho ambiental, através da redução de fontes de desperdícios e emissão; c) reduzir impacto ambiental por todo ciclo de vida de produto através de um desenho ambiental com baixo custo efetivo. 
Tabela 6: Avaliação do retorno financeiro da implementação dos móveis coletores de resíduos.

\begin{tabular}{|c|c|c|c|c|c|c|}
\hline \multirow{3}{*}{$\begin{array}{l}\text { Problema } \\
\text { Solução }\end{array}$} & \multirow{3}{*}{$\begin{array}{l}\text { Problema } \\
\text { Solução }\end{array}$} & \multicolumn{4}{|c|}{ Análise Financeira } & \multirow{3}{*}{$\begin{array}{c}\text { Benefício } \\
\text { Ambiental }\end{array}$} \\
\hline & & \multirow{2}{*}{$\begin{array}{c}\text { Investimento } \\
(\mathbf{R} \$)\end{array}$} & \multicolumn{2}{|c|}{$\begin{array}{c}\text { Receita Gerada } \\
\text { (R\$) }\end{array}$} & \multirow{2}{*}{$\begin{array}{c}\text { Pay-back } \\
\text { (meses) }\end{array}$} & \\
\hline & & & Mês & Ano & & \\
\hline $\begin{array}{c}\text { Desperdício da } \\
\text { cola branca }\end{array}$ & $\begin{array}{l}\text { Móvel para } \\
\text { otimização } \\
\text { do uso da } \\
\text { cola branca }\end{array}$ & 19,10 & 20,07 & 240,91 & $<1$ & $\begin{array}{l}\text { - Diminuição no } \\
\text { consumo de cola; } \\
\text { - Diminuição da } \\
\text { geração } \\
\text { resíduos. }\end{array}$ \\
\hline $\begin{array}{c}\text { Desperdício de } \\
\text { Lixa }\end{array}$ & $\begin{array}{c}\text { Uso de } \\
\text { quatro cortes } \\
\text { na folha }\end{array}$ & 0 & 32,65 & 391,88 & 0 & $\begin{array}{l}\text { - Otimização do } \\
\text { uso do insumo. } \\
\text { - Diminuição da } \\
\text { geração } \\
\text { resíduos. }\end{array}$ \\
\hline $\begin{array}{l}\text { Acumulo de } \\
\text { resíduos } \\
\text { (serragem) no } \\
\text { chão de fábrica }\end{array}$ & $\begin{array}{l}\text { Instalação } \\
\text { de um } \\
\text { sistema de } \\
\text { coleta }\end{array}$ & 112,6 & 18,25 & 219,09 & 6 & \\
\hline $\begin{array}{l}\text { Geração e } \\
\text { acumulo de } \\
\text { resíduos de } \\
\text { MDF }\end{array}$ & $\begin{array}{l}\text { Utilização } \\
\text { de uma } \\
\text { prensa para } \\
\text { o reuso de } \\
\text { amparas de } \\
\text { MDF }\end{array}$ & 4180,00 & 235,2 & 2822,4 & 18 & $\begin{array}{ll}\text { - Diminuição no } & \text { no } \\
\text { consumo } & \text { de } \\
\text { MDF; } & \\
\text { - Diminuição na } \\
\text { geração } \\
\text { resíduos sólidos }\end{array}$ \\
\hline $\begin{array}{l}\text { Desorganização } \\
\text { no controle da } \\
\text { produção e de } \\
\text { insumos }\end{array}$ & $\begin{array}{l}\text { Controle e } \\
\text { Ordem de } \\
\text { Produção }\end{array}$ & - & - & - & - & Não se aplica. \\
\hline \multicolumn{2}{|c|}{ Total } & 4311,7 & 306,17 & 3674,28 & - & - \\
\hline
\end{tabular}

\section{CONSIDERAÇÕES FINAIS}

O presente trabalho buscou avaliar a experiência da implementação de Produção mais Limpa em uma indústria de móveis, focando nos resultados positivos que esta ferramenta pode beneficiar a empresa e algumas barreiras no processo de implementação do programa.

O diagnóstico do processo produtivo realizado através da elaboração do fluxograma da empresa, análise dos aspectos e impactos ambientais, análise dos métodos e balanço de massa, apontou pontos falhos no processo, como desperdício dos insumos (cola, lixa e MDF), ausência de controle da produção, entre outros.

Destaca-se que grande parte dos desperdícios iniciava-se pela falta de conhecimento por parte do empresário sobre os aspectos e impactos ambientais de suas atividades, além de falhas organizacionais, ou seja, a ausência de uma fiscalização e/ou controle da gerência para um uso racional dos recursos, bem como ausência de conhecimento e atitude ambiental (por exemplo, zelo pelos recursos ou critérios para se evitar desperdícios e conseqüente geração de resíduos) por parte dos funcionários. Estes fatos acarretavam, além de desperdícios significativos de materiais, na geração de resíduos sólidos, efluentes, perda da produtividade e aumento do risco para o meio ambiente e funcionários

Nesse contexto, as oportunidades de melhoria ambiental contemplaram os níveis 1 (redução na fonte) e nível 2 (reciclagem interna) acarretando na otimização do uso de recursos e a diminuição da poluição gerada. Assim houve uma otimização do uso da cola e da lixa, a 
implementação de um sistema de coleta de serragem e um sistema de reciclagem de chapas de MDF. Do ponto de vista econômico, a empresa passou a ter uma economia anual de $\mathrm{R} \$ 3.600$ a partir de um investimento de $\mathrm{R} \$ 4311$, sendo observado um período de retorno não superior a dois anos em cada estudo.

Desta forma, verifica-se que foi possível a implementação de um controle preventivo de aspectos ambientais significativos nas empresas estudadas, fornecendo elementos de discussão favoráveis para a incorporação da variável ambiental no seu processo de gestão corporativa.

Contudo nota-se a partir deste estudo de caso, que com a Produção mais Limpa foi possível a otimização do uso de recursos naturais e a diminuição de desperdícios e consequentemente da poluição gerada por um processo produtivo. Para tanto, o envolvimento dos funcionários e o apoio da alta administração estiveram diretamente associado ao sucesso do caso. Enfatiza-se que $\mathrm{o}$ apoio da equipe do IFRN no processo de investigação também foi crucial, principalmente na fundamentação técnica e cobrança para implantação das oportunidades de melhoria e no monitoramento. Todavia, o plano de continuidade das ações de $\mathrm{P}+\mathrm{L}$, passa a ter agora uma independência da equipe do IFRN, o que faz necessário um total comprometimento e apoio da alta administração nas ações do ecotime.

\section{REFERÊNCIAS}

1. ASSOCIAÇÃO BRASILEIRA DAS INDÚSTRIAS DO MOBILIÁRIO - ABIMOVEL. Panorama do Setor Moveleiro no Brasil: Informações Gerais. São Paulo, 2006. Disponível em: <http://www.abimóvel.org.br>. Acesso em: 20 jul. 2009.

2. BARBIERI, José Carlos. Gestão ambiental empresarias: conceitos, modelos e instrumentos.São Paulo, 2007.

3. CENTRO NACIONAL DE TECNOLOGIAS LIMPAS - CNTL. Curso de Formação de Consultores em Produção Mais Limpa para Pequena e Microempresa: módulo 1. Porto Alegre, 2003.

4. DONAIRE, Denis. Gestão ambiental na empresa. 2ed. São Paulo: Atlas, 1999.

5. FEDERAÇÃO DAS INDUSTRIAIS DO RIO GRANDE DO NORTE - FIERN. A situação do setor moveleiro do Rio Grande do Norte. FIERN: Natal-RN, 2004.

6. GLAVIC, Peter; LUKMAN, Rebeka. Review of sustainability terms and their definitions. Journal of Cleaner Production, v. 15, p. 1875 - 1885, February 2007.

7. GORINI, Ana Paula Fontenelle. Panorama do setor moveleiro no Brasil, com ênfase na competitividade externa a partir do desenvolvimento da cadeia industrial de produtos sólidos de madeira. BNDES, 1998. Disponível em: < http://www.bndes.gov.br >. Acesso em: 10 jul. 2009.

8. LIMA, Elaine Garcia de; SILVA, Dimas Agostinho da. Resíduos gerados em indústrias de móveis de madeira situadas no pólo moveleiro de Arapongas - PR. Curitiba, $2005 . \quad$ Disponível em: <http://ojs.c3sl.ufpr.br/ojs2/index.php/floresta/article/viewFile/2434/2036>. Acesso em: 12 jul 2009.

9. NASCIMENTO, Luis Felipe; LEMOS, Ângela Denise da Cunha; MELO, Maria Celina Abreu de. Gestão socioambiental estratégica. Porto Alegre: Bookman, 2008.

10. PIMENTA, Handson Cláudio Dias. A produção mais limpa como ferramenta em busca da sustentabilidade empresarial: um estudo de múltiplos casos em empresas do 
estado do Rio Grande do Norte, 2008. 174 f. Dissertação (Mestrado em Ciências em Engenharia de Produção) - Programa de Pós-Graduação em Engenharia de Produção, Universidade Federal do Rio Grande do Norte, Natal, 2008.

11. PÓLO DE MODERNIZAÇÃO EMPRESARIAL DAS INDUSTRIAIS DE MÓVEIS DE NATAL - POLOEMP. Estudo de viabilidade técnica e economica para criação do POLOEMP. FINEP/SEBRAE/PATIME: Natal, 1999.

12. SANTOS, Suely Xavier dos. Inserção do design em micro e pequenas empresas: o caso de duas indústrias moveleiras no estado do Rio Grande do Norte, 2007. 261 f. Dissertação (Mestrado em Engenharia da Produção) - Programa de Pós-Graduação em Engenharia de Produção, Universidade Federal do Rio Grande do Norte, Natal, 2007.

13. SLACK, Niegel; CHAMBERS Stuart; JOHNSTON, Robert. Administração da produção. São Paulo: Atlas, 1997.

14. SCHENINI, Pedro Carlos. Gestão empresarial sócio ambiental. Florianópolis: Nupegema, 2005.

15. SCHNEIDER, Vania Elizabete. et al. Gerenciamento ambiental na indústria moveleira estudo de caso no município de Bento Gonçalves. In: ENCONTRO NACIONAL DE ENGENHARIA DE PRODUÇÃO, 23, 2003, Ouro Preto. Anais... Ouro Preto: ABEPRO, 2005. p. 1-7.

16. SERVIÇO DE APOIO ÀS MICRO E PEQUENAS EMPRESAS - SEBRAE. Metodologia de produção mais Limpa e barreiras. Rio de Janeiro: SEBRAE/CEBDS, 2005. 89 p.

17. SILVA, Gisele Cristina Sena; MEDEIROS, Denise Dumke. Metodologia de Checkland aplicada à implementação da Produção mais Limpa em Serviços. Gestão e Produção. v. 13, n. 3, p. 411-422, Set./Dez. 2006.

18. SILVA, Edna Lúcia da; MENEZES, Estera Muszkat. Metodologia da pesquisa e elaboração de dissertação. 2ed. Florianópolis: Laboratório de Ensino a Distância da UFSC, 2001.

19. SILVA FILHO, Júlio Cezar Gomes; SICSÚ, Abraham Benzaquem. Produção Mais Limpa: uma ferramenta da gestão ambiental aplicada às empresas nacionais. In: ENCONTRO NACIONAL DE ENGENHARIA DE PRODUÇÃO, 23, 2003, Ouro Preto. Anais... Ouro Preto: ABEPRO, 2003. p. 1-8.

20. UNITED NATIONS ENVIRONMENTAL PROGRAMME - UNEP. Understanding Cleaner Production: Related Concepts. Disponível em: <http://www.uneptie.org/pc/cp/understanding_cp/related_concepts.htm\#3> Acesso em 20 out. 2007.

21. VALENÇA, Antonio Carlos de Vasconcelos; PAMPLONA, Leonardo de Moura Perdigão; SOUTO, Sabrina Weber. Os novos desafios para a indústria moveleira no Brasil. Rio de Janeiro: BNDES, 2002.

22. WEIHS, Gerhard; WEISSEL Wolfgang. Ecoprofit - profits from cleaner production: project replication guieline. Eitweg: CENTRE OF ENVIRONMENTAL TRAINING AND INTERNACIONAL CONSULTING, 2005. 61 p.

\section{AGRADECIMENTOS}

FUNCERN, SEBRAE-RN, IEL-RN e ao APL da Indústria Moveleira da Grande Natal-RN. 